\title{
PERENCANAAN DAN OPTIMASI PENJADWALAN PROYEK REVITALISASI MASJID AL-WUSTHO KOTA SURAKARTA DENGAN SOFTWARE PRIMAVERA 6.0
}

\author{
Setiono $^{1)}$, Muji Rifai ${ }^{2}$, Ranno Fachryanto ${ }^{3)}$ \\ 1) 2) Dosen Program Studi Teknik Sipil, Fakultas Teknik, Universitas Sebelas Maret Surakarta \\ 3) Mahasiswa Program Studi Teknik Sipil, Fakultas Teknik, Universitas Sebelas Maret Surakarta \\ Program Studi Teknik Sipil, Fakultas Teknik, Universitas Sebelas Maret Surakarta \\ J1. Ir. Sutami 36A, Surakarta 57126. Telp: 0271-634524 \\ Email: rannofachryanto@gmail.com
}

\begin{abstract}
The Complication and complexity of every construction project developments are constantly increasing, therefore optimizing time and cost with certain resource allocations are crucial. Methods that is useful to shorten project completion with minimum cost include using the Time Cost Trade Off (TCTO). In Revitalization Project of Al-Wustho Mosque in Surakarta City, the method that is used to shorten project completion is by using the addition of working time and the addition of workers. The utilization of Primavera 6.0 software can ease the planning and scheduling process. The output that is produced from Primavera 6.0 program are Gantt Chart, Network. Diagram, Critical Path, Resources and so forth that can be used for project controlling. The results from the conducted analysis, the project duration obtained by adding working time are 131 days with additional cost of $\mathrm{Rp} 91.531 .786,29$, increasing the total cost to $\mathrm{Rp} 2.985 .367 .859,79$. Whereas the project duration obtained by adding workers are 114 days with additional cost of $\mathrm{Rp} 162.312 .628,34$, increasing the total cost to $\mathrm{R} p 3.056 .148 .701,84$. It can be concluded that by using the addition of workers method will shorten project duration in addition of more cost compared with the addition of working time method.
\end{abstract}

Keywords: addition of working time, addition of workers, optimization, time cost trade off.

\begin{abstract}
Abstrak
Tingkat kerumitan dan kompleksitas dalam setiap pembangunan proyek konstruksi bertambah dengan konstan, sehingga melakukan optimasi waktu dan biaya dengan alokasi sumber daya tertentu menjadi hal yang penting. Metode yang dapat berguna untuk mempercepat durasi penyelesaian proyek termasuk dengan menggunakan Time Cost Trade Off (TCTO). Pada Proyek Revitalisasi Masjid Al-Wustho Kota Surakarta, metode yang digunakan untuk mempercepat penyelesaian proyek direncanakan dengan penambahan jam kerja dan penambahan tenaga kerja. Penggunaan software Primavera 6.0 dapat memudahkan proses perencanaan dan penjadwalan. Output yang dihasilkan dari program Primavera 6.0 berupa Gantt Chart, Network Diagram, Critical Path, Resources dan lain sebagainya yang dapat digunakan dalam pengendalian proyek. Dari hasil analisis yang dilakukan diperoleh durasi proyek dengan menambah jam kerja yaitu 131 hari dengan biaya tambahan sebesar Rp 91.531.786,29 sehingga biaya proyek bertambah menjadi Rp 2.985.367.859,79. Sedangkan durasi proyek yang diperoleh dengan menambah jam kerja yaitu 114 hari dengan biaya tambah sebesar Rp 162.312.628,34 sehingga biaya proyek bertambah menjadi Rp 3.056.148.701,84. Sehingga dapat disimpulkan bahwa dengan menggunakan metode penambahan tenaga kerja dapat mengurangi durasi proyek dengan menambah biaya yang lebih banyak dibandingkan dengan metode penambahan jam kerja.
\end{abstract}

Kata Kunci: optimasi, penambahan jam kerja, penambahan tenaga kerja, time cost trade off.

\section{PENDAHULUAN}

Proyek merupakan suatu rangkaian aktivitas yang memiliki tujuan dan sasaran tertentu serta dibatasi oleh rentang biaya, waktu, dan sumber daya. Setiap proyek tersusun atas rangkaian kegiatan serta setiap proyek bersifat unik dan tidak terjadi berulang kali. Penyelesaian sebuah proyek harus sesuai dengan persyaratan spesifikasi yang telah dirancang untuk memenuhi kebutuhan pelanggan (Soeharto,1995).

Setiap proyek dibatasi oleh biaya, waktu serta spesifikasi mutu yang direncanakan dalam proses mencapai tujuan. Ketiga hal tersebut saling berhubungan satu sama lain sehingga dapat disebut sebagai triple constraint, yang dapat dijelaskan sebagai berikut:

1. biaya (anggaran), setiap kegiatan dalam suatu proyek diharuskan menggunakan biaya yang tidak melebihi anggaran yang telah disetujui,

2. jadwal (waktu), proses pelaksanaan suatu proyek harus dimulai dan diakhiri dengan kurun waktu yang telah ditentukan,

3. mutu (kinerja), setiap produk hasil proyek harus memenuhi syarat kriteria dan spesifikasi (Soeharto,1995). 
Seiring dengan perkembangan zaman, tingkat kerumitan dan kompleksitas dalam setiap pembangunan proyek konstruksi semakin bertambah. Setiap proyek perlu memanfaatkan biaya dan waktu secara optimal dengan alokasi sumber daya tertentu sehingga perlu adanya pelaksanaan fungsi manajemen (perencanaan, pelaksanaan dan pengendalian) dengan menggunakan sumber daya yang ada secara efektif guna memenuhi tujuan yang telah digariskan (Andhika, 2017).

Manajemen proyek memiliki artian lebih dari sekedar menjaga hubungan triple constraint proyek tetap sesuai dengan waktu, biaya serta mutu yang sesuai rencana, hal tersebut juga menjadi sebuah garis dasar untuk pekerjaan di masa yang akan datang (Poornima \& Chitra, 2020). Manajemen proyek mencakup perencanaan penjadwalan yang direncanakan dengan menyesuaikan tiap pekerjaan dengan waktu dan sumber daya yang ada secara optimal. Penjadwalan dapat diartikan sebagai pengalokasian sejumlah sumber daya (resource) untuk melakukan sejumlah tugas atau operasi dalam jangka waktu tertentu dan merupakan proses pengambilan keputusan yang peranannya sangat penting dalam industri manufaktur dan jasa yaitu mengalokasikan sumber-sumber daya yang ada agar tujuan dan sasaran perusahaan lebih optimal (Baker \& Trietsch, 2009).

Metode penyusunan jadwal yang biasa digunakan adalah diagram jaringan kerja atau network planning. Pada metode jaringan kerja terdapat jalur kritis, dimana pada jalur tersebut terdapat rangkaian kegiatan kritis, dimulai dari kegiatan pertama sampai pada kegiatan terakhir proyek (Soeharto, 1995). Jika keterlambatan terjadi pada kegiatan/aktivitas yang terdapat pada jalur kritis maka keseluruhan proyek juga akan mengalami keterlambatan (Widiasanti \& Lenggogeni, 2013). Oleh karena itu diperlukan opsi untuk menghadapi masalah tersebut dengan melakukan percepatan pada penyelesaian proyek dengan biaya minimum. Metode optimasi yang dapat digunakan adalah metode pertukaran waktu dan biaya atau Time Cost Trade Off (TCTO). Penelitian yang dilakukan oleh Pawiro, D. A., dkk., (2014) terhadap proyek pembangunan Gedung Pusat Kegiatan Mahasiswa Universitas Diponegoro Semarang menggunakan metode Time Cost Trade Off (TCTO). Analisis yang dilakukan dapat mempercepat durasi serta mengurangi biaya total proyek secara optimum.

Penjadwalan sebuah proyek konstruksi memiliki tingkat kompleksitas tergantung dari jenis-jenis dan jumlah pekerjaan yang ada di dalam sebuah proyek. Semakin banyak jenis pekerjaan yang ada maka proses penjadwalan akan semakin rumit jika tanpa dibantu sebuah alat atau tools. Penjadwalan proyek konstruksi dikelola dengan bantuan program Primavera P6. Primavera P6 merupakan versi terbaru dari software Primavera dengan fitur-fitur yang memudahkan dalam proses manajemen sebuah proyek. Program ini dapat melakukan administrasi usaha, administrasi barang, kerja sama, dan kapasitas kontrol, serta dapat berkoordinasi dengan pemrograman lainnya seperti Oracle dan SAP (Paliwal \& Chouriya, 2019).

Tujuan dari penelitian ini adalah untuk menghitung dan membandingkan perkiraan total waktu dan biaya yang didapatkan untuk penyelesaian proyek sebelum dan setelah dilakukan optimasi. Penelitian dilakukan terhadap Proyek Revitalisasi Masjid Al-Wustho Kota Surakarta dengan menggunakan program Primavera Project Planner P6 atau dapat disingkat dengan Primavera P6.

\section{METODE}

\section{Time Cost Trade Off}

Penelitian ini menggunakan metode Time Cost Trade Off (TCTO). Metode ini dilakukan dengan mengaplikasikan percepatan pada kegiatan/aktivitas yang berada pada lintasan kritis saja, tujuannya agar percepatan durasi proyek yang maksimal dan pengeluaran biaya yang minimal dapat tercapai (Arvianto dkk., 2017).

\section{Perhitungan Produktivitas Pekerjaan}

Salah satu faktor yang menentukan keberhasilan dari suatu proyek konstruksi bergantung pada pengelolaan sumber daya yang efektif, dimana pekerja adalah salah satunya. Untuk menentukan nilai produktivitas pekerjaan digunakan rumus: (Suherman \& Hariono, 2016)

$$
\text { Produktivitas Harian }=\frac{\text { Volume }}{\text { Durasi Normal }} \text { …….......... [1] }
$$


Produktivitas Per Jam $=\frac{\text { Produktivitas Harian }}{\text { Jam Kerja Harian }}$

Produktivitas Harian Sesudah Crash $=($ Jam Kerja Harian $\times$ Produktivitas Per Jam $)+(a \times b \times$ Produktivitas Per Jam $)$ [3]

Crash Duration $=\frac{\text { Volume }}{\text { Produktivitas Harian Sesudah Crash }}$ $\ldots[4]$

Cost Slope $=\frac{\text { Crash cost }- \text { normal cost }}{\text { normal duration }- \text { crash duration }}$

Keterangan:

$\mathrm{a} \quad=$ lama penambahan jam kerja (lembur)

$\mathrm{b}=$ koefisien penurunan produktivitas akibat penambahan jam kerja (lembur)

\section{Primavera P6}

Analisis data-data yang telah diperoleh menggunakan program Primavera P6. Semua data yang menyangkut pelaksanaan proyek akan dimasukan ke dalam program Primavera P6, kemudian program akan mengalkulasi serta menyusun hasil yang diharapkan. Hasil yang akan diperoleh adalah diagram jaringan kerja/network planning proyek, gantt chart, serta jalur kritis dari diagram tersebut. Diagram alir penelitian dapat dilihat pada Gambar 1.

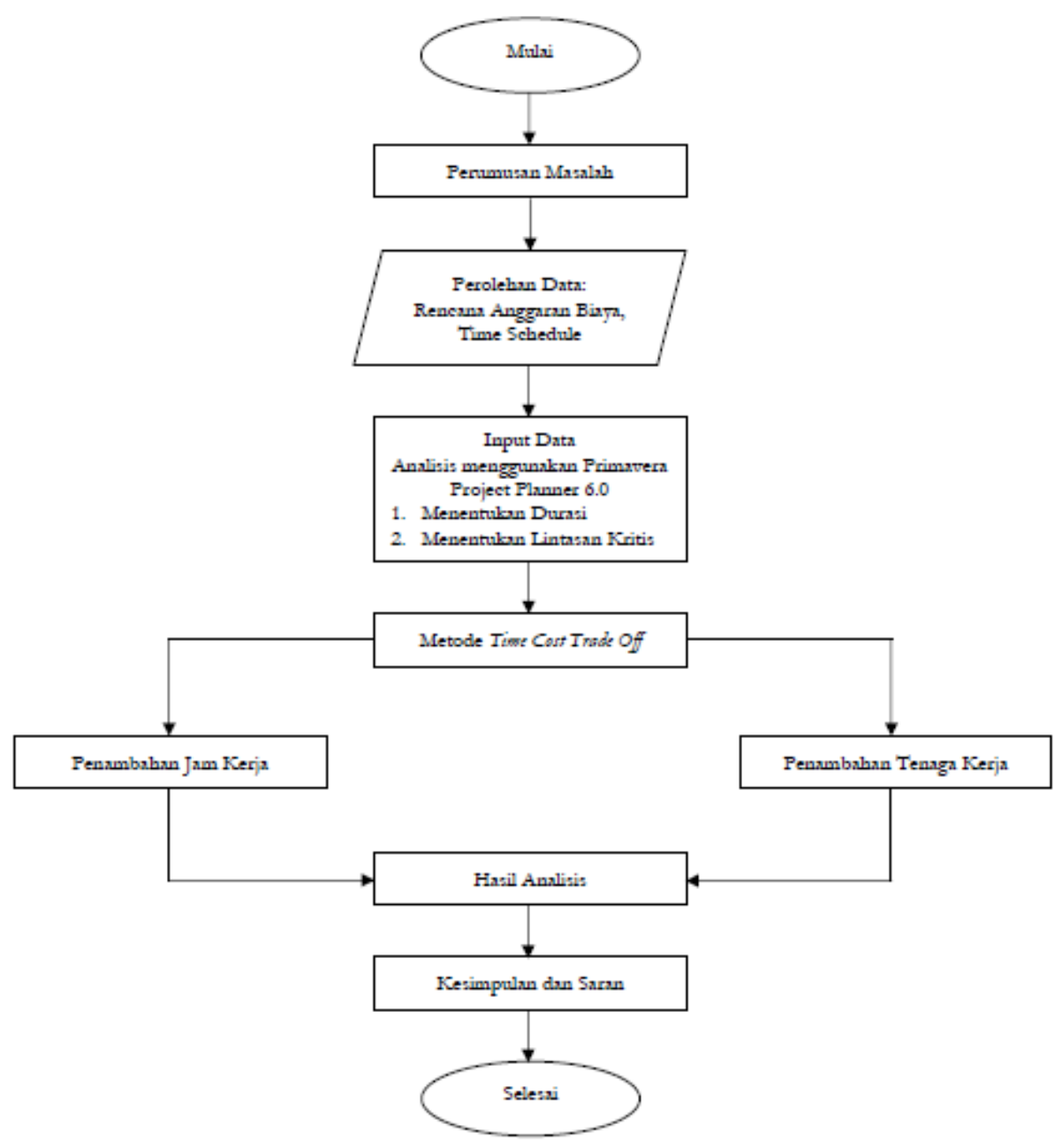

Gambar 1. Diagram alir tahap metode pengerjaan tugas akhir

HASIL DAN PEMBAHASAN

Sumber: Hasil Penelitian

Penambahan Jam Kerja (Waktu Lembur)

Perencanaan penambahan jam kerja/waktu lembur dengan dengan waktu lembur berdasarkan PP No. 35 Tahun 2021 Pasal 26 adalah menggunakan 8 jam kerja normal dan 1 jam istirahat $(08.00$ - 17.00), sedangkan waktu lembur hanya dapat dilakukan paling lama 4 (empat) jam dalam 1 (satu) hari dan 18 (delapan belas) jam dalam 1 (satu) 
minggu. Standar upah untuk waktu lembur berdasarkan PP No. 35 Tahun 2021 Pasal 31 adalah upah untuk jam kerja lembur pertama sebesar 1,5 (satu setengah) kali upah 1 jam kerja normal. Sedangkan upah untuk setiap jam kerja lembur berikutnya (jam ke-2 dan seterusnya) sebesar 2 (dua) kali upah 1 jam kerja normal. Perhitungan untuk kegiatan-kegiatan kritis yang akan dipercepat dihitung berdasarkan biaya langsung pekerjaan sehingga cost slope atau penambahan biaya pekerjaan dapat diperoleh.

Perhitungan durasi yang dilakukan untuk mempercepat pekerjaan pada jalur kritis dengan menambahkan jam kerja dapat dijelaskan sebagai berikut:

a. waktu kerja normal: $8 \mathrm{jam} / \mathrm{hari}$,

b. jumlah penambahan jam kerja lembur: 3 jam/hari,

c. produktivitas kerja lembur: $75 \%$, dikarenakan faktor kelelahan, keterbatasan penerangan dan udara yang lebih dingin sehingga menyebabkan menurunnya produktivitas pekerjaan (Arvianto dkk., 2017).

Berikut adalah contoh perhitungan durasi dan biaya akibat crashing menurut Rizky dkk., (2019):

(Analisis Harga Satuan Pekerjaan diperoleh dari dokumen proyek)

A5. Pembongkaran Gudang Belakang

1. Normal Cost.
a. Volume Pekerjaan
b. Upah
c. Normal Duration
$=15,00 \mathrm{~m}^{2}$,
d. Normal Cost
$=\mathrm{Rp} 175.500,00$,
$=4$ hari,
$=(\mathrm{a} \times \mathrm{b})$

2. Crash Duration:
e. Produktivitas Harian
f. Produktivitas per Jam
$=(\mathrm{a}: \mathrm{c})=(15: 4)=3,75 \mathrm{~m}^{2} /$ hari,
g. Produktivitas Harian Crash $=(\mathrm{e}+(4 \times \mathrm{f} \times 75 \%))=(3,75+(3 \times 0,4688 \times 0,75))=4,6069 \mathrm{~m}^{2} /$ hari,
h. Crash duration
$=(\mathrm{a}: \mathrm{g})=(15: 4,6069)=2,9091 \sim 3$.

$=(15 \times 175.500)=\operatorname{Rp} 2.632 .500$,

3. Crash Cost.

i. Upah Normal per Jam = b x f

$=\operatorname{Rp} 175.500 \times 0,4688$

$=\operatorname{Rp} 82.265,62$,

j. Upah Lembur 4 Jam

$$
=(1,5 \times \mathrm{i})+(2 \times \mathrm{i} \times 3)
$$

$=(1,5 \times 82.265,62)+(2 \times \operatorname{Rp} 82.265,62 \times 2)$

k. Total Upah Lembur

$=\mathrm{Rp} 452.461,00$,

$=3 \times \mathrm{Rp} 452.461$

$=\operatorname{Rp} 1.357 .383$

1. Total Crash Cost

$=\mathrm{k}+\mathrm{d}$

$=\mathrm{Rp} 1.357 .383+\mathrm{Rp} 2.632 .500$

$=\mathrm{Rp} 3.989 .883$

4. Cost Slope:

m. Cost Slope

$$
\begin{aligned}
& =\frac{\text { Crash Cost }- \text { Normal Cost }}{\text { Normal Duration-Crash Duration }} \\
& =\frac{l-d}{c-h} \\
& =\frac{3.989 .883-2.632 .500}{4-3} \\
& =\text { Rp1.357.383,00 }
\end{aligned}
$$


Tabel 1. Rekapitulasi perhitungan dengan metode 1

\begin{tabular}{clcrrr}
$\begin{array}{c}\text { Kode } \\
\text { Analisa }\end{array}$ & Uraian Pekerjaan & $\begin{array}{c}\text { Crash } \\
\text { Duration } \\
\text { (hari) }\end{array}$ & Crash Cost (Rp) & $\begin{array}{c}\text { Total Crash } \\
\text { Cost (Rp) }\end{array}$ & Cost Slope (Rp) \\
\hline A & Pekerjaan Persiapan & 6 & 1.420 .495 & 4.212 .295 & 1.420 .495 \\
B & Pekerjaan Tanah dan Galian & 25 & 3.487 .104 & 11.130 .150 & 672.285 \\
C & Pekerjaan Halaman Masjid & 41 & 42.482 .854 & 139.485 .889 & 7.217 .921 \\
D & Pekerjaan Bangunan Menara & 5 & 5.673 .696 & 17.296 .892 & 2.732 .671 \\
E & Pekerjaan Bangunan Maligin & 24 & 2.548 .064 & 8.045 .784 & 1.328 .478 \\
F & Pekerjaan Serambi dan Ruangan & 20 & 8.124 .316 & 25.083 .767 & 6.635 .185 \\
G & Pekerjaan Renovasi R. Wudhu & 7 & 7.214 .016 & 24.156 .239 & 4.871 .262 \\
H & Pekerjaan Taman & 3 & 6.264 .527 & 19.731 .461 & 2.253 .757 \\
\hline
\end{tabular}

\section{Penambahan Tenaga Kerja}

Perencanaan penambahan jumlah tenaga kerja diartikan sebagai jumlah pekerja yang ditambahkan untuk melaksanakan suatu kegiatan/aktivitas tanpa menambahkan jam kerja. Dalam merencanakan penambahan jumlah tenaga kerja perlu memperhatikan ruang kerja yang ada, karena menambahkan tenaga kerja untuk melaksanakan kegiatan tertentu tidak dapat mengganggu penggunaan tenaga kerja untuk kegiatan lain yang sedang berjalan pada waktu bersamaan. Perencanaan penambahan jumlah tenaga kerja juga perlu diiringi dengan penambahan tenaga pengawasan, karena produktivitas kerja cenderung menurun seiring dengan berkurangnya ruang kerja yang tersedia.

Perhitungan durasi untuk mempercepat pekerjaan pada jalur kritis dengan menambahkan tenaga kerja dapat dijelaskan menurut Raharjo \& Musyafa (2018) sebagai berikut:

(Analisis Harga Satuan Pekerjaan diperoleh dari dokumen proyek)

A5. Pembongkaran Gudang Belakang

1. Data Pekerjaan:
a. Volume pekerjaan
$=15,00 \mathrm{~m}^{2}$
b. Upah
$=\operatorname{Rp} 175.500$
c. Normal Duration
$=4$ hari

2. Kapasitas Kerja per Hari:
a. Koefisien tenaga kerja:
b. Pekerja
$=0,2$
c. Kepala Tukang
$=0,02$
d. Mandor
$=0,02$
e. Kapasitas Kerja
$=\frac{1}{\text { Koefisien Tenaga Kerja }}$
f. Pekerja
$=\frac{1}{0,2}=5 \mathrm{~m}^{2} /$ hari
g. Kepala Tukang
$=\frac{1}{0,02}=50 \mathrm{~m}^{2} /$ hari
h. Mandor
$=\frac{1}{0,02}=50 \mathrm{~m}^{2} /$ hari

3. Indeks Tenaga Kerja per Hari:
a. Indeks Tenaga Kerja
$=\frac{\text { Volume Pekerjaan }}{\text { Kapasitas Kerja }+ \text { Durasi Pekerjaan }}$
$=\frac{a}{d \times c}$
b. Pekerja
$=\frac{15}{5 \times 4}=0,75 \mathrm{OH}$
c. Kepala Tukang
$=\frac{15}{50 \times 4}=0,075 \mathrm{OH}$
d. Mandor
$=\frac{15}{50 \times 4}=0,075 \mathrm{OH}$ 
4. Normal Cost:
a. Harga Upah
$=$ Jumlah Tenaga Kerja x Harga Satuan
b. Pekerja
$=0,75 \times \operatorname{Rp} 45.000$
$=\operatorname{Rp} 33.750,00$
c. Kepala Tukang
$=0,075 \times \operatorname{Rp} 65.000$
$=\mathrm{Rp} 4.875,00$
d. Mandor
$=0,075 \times \operatorname{Rp} 70.000=\operatorname{Rp} 5.250,00$
Jumlah
g. Normal Cost
$=$ Harga Upah x Normal Duration
$=\mathrm{Rp} 43.875,00$
$=\mathrm{f} \times \mathrm{c}$
$=\mathrm{Rp} 43.875 \times 4$
$=\operatorname{Rp} 175.500,00$

5. Crash Duration:
a. Durasi Crashing dengan menambahkan 1 pekerja

$$
\begin{aligned}
& =\frac{\text { Volume Pekerjaan }}{\text { Kapasitas Kerja } \times(\text { Jumlah Tenaga Kerja }+1)} \\
& =\frac{a}{d \times(e+1)}
\end{aligned}
$$
b. Pekerja
$=\frac{15}{50 \times(0,75+1)}=1,71 \sim 2$ hari
c. Kepala Tukang
$=\frac{15}{50 \times(0,075+1)}=0,28 \sim 0$ hari
d. Mandor
$=\frac{15}{50 \times(0,075+1)}=0,28 \sim 0$ hari

Digunakan durasi yang terpanjang yaitu 2 hari.

6. Crash Cost.
h. Upah Pekerja
Pekerja
Kepala Tukang
Mandor
Jumlah
i. Crash Cost = Jumlah Upah $\mathrm{x}$ Durasi Crash
$=$ Upah Satuan $\mathrm{x}$ Jumlah Tenaga
$=\operatorname{Rp} 45.000,00 \times 1,75=\operatorname{Rp} 78.750,00$
$=\operatorname{Rp} 65.000,00 \times 1,075=\operatorname{Rp} 69.875,00$
$=\operatorname{Rp} 70.000,00 \times 1,075=\operatorname{Rp} 75.250,00$
$=\mathrm{i} \times \mathrm{h}$
$=\mathrm{Rp} 223.875,00 \times 2$
j. Total Crash Cost
$=\operatorname{Rp} 447.750,00$
$=$ Normal Cost + Crash Cost
$=\mathrm{g}+\mathrm{j}$
$=\mathrm{Rp} 175.500,00+\mathrm{Rp} 447.750$
$=\operatorname{Rp} 623.250,00$

7. Cost Slope:

k. Cost Slope

$$
\begin{aligned}
& =\frac{\text { Crash Cost }- \text { Normal Cost }}{\text { Normal Duration-Crash Duration }} \\
& =\frac{j-g}{c-h} \\
& =\frac{R p 623.250,00-R p 175.500,00}{4-2} \\
& =\operatorname{Rp} 223.875,00
\end{aligned}
$$


Tabel 2. Rekapitulasi perhitungan dengan metode 2

\begin{tabular}{clcrrr}
\hline $\begin{array}{c}\text { Kode } \\
\text { Analisa }\end{array}$ & Uraian Pekerjaan & $\begin{array}{c}\text { Crash } \\
\text { Duration } \\
\text { (hari) }\end{array}$ & Crash Cost (Rp) & $\begin{array}{c}\text { Total Crash } \\
\text { Cost (Rp) }\end{array}$ & Cost Slope (Rp) \\
\hline A & Pekerjaan Persiapan & 4 & 868.950 & 3.660 .750 & 434.475 \\
B & Pekerjaan Tanah dan Galian & 17 & 12.379 .832 & 20.022 .878 & 2.478 .748 \\
C & Pekerjaan Halaman Masjid & 41 & 80.195 .385 & 177.198 .420 & 28.105 .582 \\
D & Pekerjaan Bangunan Menara & 22 & 16.539 .852 & 28.163 .048 & 10.814 .077 \\
E & Pekerjaan Bangunan Maligin & 18 & 14.812 .657 & 22.029 .281 & 4.555 .936 \\
F & Pekerjaan Serambi dan Ruangan & 14 & 8.843 .591 & 25.803 .042 & 7.618 .010 \\
G & Pekerjaan Renovasi R. Wudhu & 7 & 20.327 .220 & 37.269 .443 & 10.360 .798 \\
H & Pekerjaan Taman & 8 & 18.692 .720 & 32.159 .654 & 12.363 .110 \\
\hline
\end{tabular}

\section{Analisis Biaya}

Setelah melakukan optimasi dengan melakukan crashing terhadap aktivitas-aktivitas yang berada pada jalur kritis, maka selanjutnya adalah perhitungan biaya langsung dan tidak langsung. Biaya langsung setelah dilakukan crashing cenderung naik sedangkan untuk biaya tidak langsungnya menurun. Besaran biaya overhead dan profit pada penelitian ini diambil 15\% dari RAB. Berdasarkan Perpres 70/2012 Pasal 92 ayat 3 tentang Penyesuaian Harga menyatakan bahwa Koefisien Tetap yang terdiri dari biaya overbead dan profit apabila harga penawaran tidak mencantumkan besarannya maka koefisien tetapnya sebesar 0,15 (15\%), Dengan biaya overhead sebesar 5\% dan profit sebesar 10\% dari RAB.

Adapun analisis biaya sebelum dan setelah optimasi adalah sebagai berikut:

Diketahui:
a. Nilai RAB
$=\mathrm{Rp} 2.516 .379 .194,35$
b. Profit $(10 \%)$
$=\mathrm{Rp} 2.516 .379 .194,35 \times 10 \% \quad=\mathrm{Rp} 251.637 .919,43$
c. Overbead (5\%)
$=\mathrm{Rp} 2.516 .379 .194,35 \times 5 \% \quad=\mathrm{Rp} 125.818 .959,72$

1. Biaya Proyek Kondisi Normal
a. Durasi Proyek
$=154$ hari
b. Biaya Langsung
$=\mathrm{Rp} 2.516 .379 .194,35$
c. Biaya Tidak Langsung: Overhead + Profit
$=\operatorname{Rp} 377.456 .879,15$
d. Biaya Overhead per hari
$=$ Rp125.818.960,72 / 154 hari $=\operatorname{Rp} 817.006,23 /$ hari
e. Total Biaya Proyek
$=$ Biaya Langsung + Biaya Tidak Langsung
$=\mathrm{Rp} 2.516 .379 .194,35+\mathrm{Rp} 377.456 .879,15=\mathrm{Rp} 2.893 .836 .073,50$

2. Biaya Proyek dengan Crashing Metode 1
a. Durasi Baru Proyek
$=131$ hari
b. Durasi Percepatan
$=154-131=23$ hari
c. Biaya Langsung
$=\mathrm{Rp} 2.593 .423 .269,97$
d. Biaya Tidak Langsung: Overhead
$=$ Durasi Baru Proyek x Biaya Overhead per hari
Profit
Overhead + Profit
$=131 \times \operatorname{Rp} 817.006,23=\operatorname{Rp} 107.027 .816,38$
$=\mathrm{Rp} 251.637 .919,43$
e. Total Biaya Proyek
$=\mathrm{Rp} 358.665 .735,82$
$=$ Biaya Langsung + Biaya Tidak Langsung
$=\mathrm{Rp} 2.593 .423 .269,97+\mathrm{Rp} 358.665 .735,82=\mathrm{Rp} 2.952 .089 .005,79$

3. Biaya Proyek dengan Crashing Metode 2
a. Durasi Baru Proyek
$=114$ hari
b. Durasi Percepatan
$=154-114=40$ hari
c. Biaya Langsung
d. Biaya Tidak Langsung: Overhead
$=\mathrm{Rp} 2.711 .372 .071,97$
Profit
Overbead + Profit
e. Total Biaya Proyek
$=$ Durasi Baru Proyek x Biaya Overbead per hari
$=114 \times$ Rp817.006,23 $=$ Rp93.138.710,44
$=\operatorname{Rp} 251.637 .919,43$
$=\mathrm{Rp} 344.776 .629,87$
$=$ Biaya Langsung + Biaya Tidak Langsung
$=\mathrm{Rp} 2.711 .372 .071,97+\mathrm{Rp} 344.776 .629,87=\mathrm{Rp} 3.056 .148 .701,84$


Berikut adalah tabel rekapitulasi perbandingan durasi, biaya langsung dan tidak langsung serta biaya total antara proyek dengan kondisi normal dan proyek setelah dilakukan optimasi.

Tabel 3. Perbandingan biaya total proyek

\begin{tabular}{lccrr}
\hline & $\begin{array}{c}\text { Durasi } \\
\text { Total } \\
\text { (hari) }\end{array}$ & $\begin{array}{c}\text { Biaya Langsung } \\
\mathbf{( R p )}\end{array}$ & $\begin{array}{c}\text { Biaya Tidak } \\
\text { Langsung (Rp) }\end{array}$ & Biaya Total (Rp) \\
\hline Kondisi Proyek Normal & 154 & $2.516 .379 .194,41$ & $377.456 .879,15$ & $2.893 .836 .073,50$ \\
Optimasi Metode 1 & 131 & $2.626 .702 .124,97$ & $358.665 .735,82$ & $2.952 .089 .005,79$ \\
Optimasi Metode 2 & 114 & $2.711 .372 .071,97$ & $344.776 .629,87$ & $3.056 .148 .701,84$ \\
Selisih Metode 1 & 23 & $77.044 .075,62$ & $18.791 .143,33$ & $58.252 .932,29$ \\
Selisih Metode 2 & 40 & $194.992 .877,62$ & $32.680 .249,27$ & $162.312 .628,34$ \\
\hline
\end{tabular}

\section{PEMBAHASAN}

Dari hasil analisis percepatan atau crashing yang dilakukan dengan dua metode percepatan, penelitian yang dilakukan penulis hanya dapat mempercepat durasi proyek tanpa mengurangi biaya total proyek sehingga penelitian yang dilakukan penulis belum dapat dikatakan berhasil. Hal ini dapat disebabkan oleh beberapa hal, contohnya adalah karena kurang adanya beberapa metode atau skenario tambahan untuk memperoleh hasil analisis yang optimum serta penulis menganggap bahwa komponen mutu merupakan sesuatu yang sudah memiliki spesifikasi teknis tertentu sehingga analisis optimasi yang dilakukan hanya menggunakan komponen waktu dan biaya saja.

\section{SIMPULAN}

Berdasarkan hasil analisis data yang telah dilakukan, maka kesimpulan yang dapat diperoleh adalah sebagai berikut:

1. Total durasi penyelesaian proyek menggunakan Time Cost Trade Off dengan optimasi metode 1 penambahan jam kerja adalah 131 hari dan total durasi penyelesaian proyek menggunakan optimasi metode 2 penambahan tenaga kerja adalah 114 hari.

2. Total biaya penyelesaian proyek menggunakan Time Cost Trade Off dengan optimasi metode 1 penambahan jam kerja adalah Rp2.952.089.005,79 dan total biaya penyelesaian proyek menggunakan optimasi metode 2 penambahan tenaga kerja adalah Rp3.056.148.701,84.

3. Perbandingan durasi waktu hasil optimasi menunjukkan bahwa penyelesaian proyek menjadi lebih cepat yaitu 131 hari dengan metode 1 dan 114 hari dengan metode 2, jika dibandingkan dengan durasi proyek eksisting yaitu 154 hari. Sedangkan biaya penyelesaian proyek mengalami kenaikan menjadi sebesar Rp2.952.089.005,79 (metode 1) dan Rp3.056.148.701,84 (metode 2) jika dibandingkan dengan biaya proyek eksisting yaitu sebesar Rp2.893.836.073,50.

\section{REKOMENDASI}

Beberapa saran yang dapat dilakukan apabila terdapat penelitian selanjutnya yang masih berkaitan dengan penelitian ini adalah sebagai berikut:

1. Penelitian selanjutnya dapat menggunakan program Primavera Project Planner P6 untuk melakukan optimasi waktu dan biaya proyek.

2. Penelitian selanjutnya dapat melakukan analisis percepatan pada pekerjaan yang berada di jalur kritis yang hanya memiliki cost slope yang tinggi saja sehingga biaya total proyek tidak mengalami kenaikan.

3. Penelitian selanjutnya dapat menerapkan beberapa metode atau skenario tambahan untuk memperoleh hasil analisis yang optimal.

4. Penelitian selanjutnya dapat melakukan optimasi pada proyek yang masih berjalan sehingga hasil analisis dapat disampaikan kepada pihak pelaksana proyek.

\section{REFERENSI}

Andhika, Mochammad., 2017, "Perencanaan Penjadwalan Proyek Pembangunan Rumah Susun Gorontalo", Universitas Hasanuddin, Makassar.

Baker, K.R. \& Trietsch, D., 2009, "Principles of Sequencing and Scheduling”, John Wiley \& Sons, New Jersey.

Kusuma, Doni Probo., 2016, "Pengendalian Biaya dan Waktu Pada Proyek Pembangunan Hotel Dengan Menggunakan Primavera Project Planner P6”, Universitas Sebelas Maret, Surakarta.

Paliwal, M. C., \& Chouriya, D., 2019. "Cost Optimization by Resource Allocation of an Ongoing Project Using Primavera P6", International Journal Online of Science, Vol. 5 No 9, pp. 2455-0108. 
Pawiro, D. A. dkk., 2014. “Optimasi Biaya dan Waktu dalam Penyusunan Jadwal Pelaksanaan Proyek (Studi Kasus Proyek Pembangunan Gedung Pusat Kegiatan Mahasiswa Universitas Diponegoro Semarang)”, Jurnal Media Komunikasi Teknik Sipil, Vol. 20 No. 2, pp. 0854-1809.

Peraturan Pemerintah Nomor 35 Tahun 2021, 2021, "Perjanjian Kerja Waktu Tertentu, Alih Daya, Waktu Kerja dan Waktu Istirahat, dan Pemutusan Hubungan Kerja".

Poornima, S., \& Chitra, G., 2020. "Monitoring of an Institutional Building Using Primavera P6 (Professional R8. 3) Software. Journal of Engineering Analysis and Design", Vol. 2 No. 1, 2, 3.

Raharjo, R. W. \& Musyafa A., 2018, "Analisis Percepatan Proyek Dengan Metode Penambahan Tenaga Kerja”, Prosiding Kolokium Program Studi Teknik Sipil FTSP UII, November 2018, ISSN 9-772477-5B3159.

Rizky F., Muhammad dkk., 2019, "Analisis Biaya Dengan Metode Time Cost Trade Off Pada Proyek Konstruksi Supermall Pakuwon Indah Phase 4 Anderson Surabaya”, Universitas 17 Agustus 1945, Surabaya.

Suherman \& Hariono, Q. P., 2016, "Optimasi Waktu Dan Biaya Menggunakan Metode Time Cost Trade Off Pada Proyek Access Road Construction and Soil Clean Up”, Jurnal Hasil Penelitian dan Karya Immiah dalam Bidang Teknik Industri, Vol. 2 No.2, Universitas Islam Negeri Sultan Syarif Kasim: Riau.

Soeharto, I., 1995, "Manajemen Proyek dari Konseptual Sampai Operasional”, Penerbit Erlangga, Jakarta.

Widiasanti, I. \& Lenggogeni., 2013, “Manajemen Konstruksi”, PT. Remaja Rosdakarya, Bandung. 